\title{
Article
}

\section{Mechanism of thermal decomposition of poly(ether ether ketone) (PEEK) from a review of decomposition studies}

Patel, Parina, Hull, T Richard, Mccabe, Richard W., Flath, Dianne, Grasmeder, John and Percy, Mike

Available at http://clok.uclan.ac.uk/1919/

Patel, Parina, Hull, T Richard ORCID: 0000-0002-7970-4208, Mccabe, Richard W., Flath, Dianne, Grasmeder, John and Percy, Mike (2010) Mechanism of thermal decomposition of poly(ether ether ketone) (PEEK) from a review of decomposition studies. Polymer Degradation and Stability, 95 (5). pp. 709718. ISSN 01413910

It is advisable to refer to the publisher's version if you intend to cite from the work. http://dx.doi.org/10.1016/j.polymdegradstab.2010.01.024

For more information about UCLan's research in this area go to http://www.uclan.ac.uk/researchgroups/ and search for <name of research Group>.

For information about Research generally at UCLan please go to http://www.uclan.ac.uk/research/

All outputs in CLoK are protected by Intellectual Property Rights law, including Copyright law. Copyright, IPR and Moral Rights for the works on this site are retained by the individual authors and/or other copyright owners. Terms and conditions for use of this material are defined in the policies page. 


\title{
Mechanism of Thermal Decomposition of
}

\section{Poly(Ether Ether Ketone) (PEEK) From a Review of Decomposition Studies}

\author{
Parina Patel, ${ }^{\mathrm{a}}$ T. Richard Hull, ${ }^{\mathrm{a}}$ Richard W. McCabe, ${ }^{\mathrm{b}}$ Dianne Flath, ${ }^{\mathrm{c}}$ John \\ Grasmeder, ${ }^{\mathrm{c}}$ and Mike Percy. ${ }^{\mathrm{c}}$ \\ a Centre for Fire and Hazards Science, School of Forensic and Investigative Science, University Of Central Lancashire, \\ Preston, PR1 2HE, UK \\ b Centre for Materials Science, School of Forensic and Investigative Science, University Of Central Lancashire, Preston, \\ PR1 2HE, UK \\ c Victrex PLC, Hillhouse International, Thornton-Cleveleys, Lancashire, FY5 4QD, UK
}

\begin{abstract}
A review of the literature on the flammability and decomposition of Poly(oxy-1,4phenyleneoxy-1,4-phenylenecarbonyl-1,4-phenylene) (PEEK) is presented. This paper provides an overview of the flammability of PEEK and its decomposition mechanisms. Based on this literature, mechanisms have been suggested which attempt to explain the products formed at each stage of PEEK decomposition and indicate the intermediates which should be formed at each of these stages.
\end{abstract}

\section{Introduction}

The widespread use of synthetic polymers has revolutionised the manufacturing industry and the range of products available. However, many synthetic polymers suffer from much greater flammability than traditional materials as the quest for synthetic polymers with good mechanical properties and low flammability continues. Poly(oxy-1,4-phenyleneoxy-1,4phenylenecarbonyl-1,4-phenylene), (PEEK), is a semi-crystalline polymer with excellent mechanical, chemical and thermal properties which permits its use in a variety of industrial applications particularly as a metal replacement. ${ }^{1}$ In addition, it has lower flammability and swells to form a significant amount of char on burning. In order to understand this behaviour and to see if further enhancement is possible, it is necessary to understand the thermal 
decomposition behaviour of PEEK. PEEK is an aromatic polyketone and is one of the commonly used engineering thermoplastic materials combining ketone and aromatic moieties. The material was invented and patented in 1978 by the Imperial Chemical Industries (ICI) company, ${ }^{2}$ but since then little work has been carried out on elucidating the thermal decomposition mechanisms of the polymer. The bulk of the work on the material's degradation and decomposition concentrates on obtaining and understanding the kinetic parameters of PEEK. ${ }^{3,4,5,6,7,8}$ Of the work which has been done relating to the thermal decomposition mechanisms, the main method of determination of the degradation pathways has concentrated on the volatile (and usually flammable), small organic molecules released into the gas phase on decomposition and few attempts have actually been made to determine the changes in composition and structure of the PEEK residue. ${ }^{9,10,11}$ The repeat units of PEEK have the following structure:

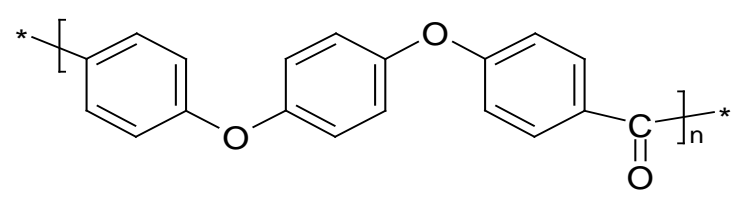

PEEK

Figure 1. Poly(oxy-1,4-phenyleneoxy-1,4-phenylenecarbonyl-1,4-phenylene) (PEEK)

The excellent thermal properties of the polymer are attributed to the stability of the aromatic backbone, which makes up the bulk of the monomer unit. ${ }^{12,13}$

Polymers containing aromatic carbon and/or heterocyclic links in the polymer main chain, such as PEEK, have certain features which relate to their pyrolysis and char yield. These features are as follows:

- Thermal stability and char yield both increase with the relative number of aromatic groups in the main chain per repeat unit of the polymer chain. ${ }^{14}$

- Pyrolysis tends to begin with scission of the weakest bonds in the bridging groups between aromatic rings. ${ }^{14}$ 
- The heat of combustion of PEEK, measured using Oxygen Bomb Calorimetry, is $31.28 \mathrm{~kJ} / \mathrm{g} .{ }^{15}$ However, in a real fire scenario, the polymer leaves a substantial ( $70 \%)$ char residue.

Using a Microscale Combustion Calorimeter (MCC), the heat release rate has been measured for some commonly used polymers (see Figure 2). Polyethylene (PE), one such polymer that is used in abundance, has a heat release rate per gram of molecule that is eight times greater than that of PEEK, making PEEK a very desirable material in situations where high temperatures may be encountered. Due to PEEK's excellent thermal and physical properties, its applications are varied and unlike commodity polymers, many of its uses are task specific; often the material is used as a composite reinforced with the addition of glass or carbon fibre.

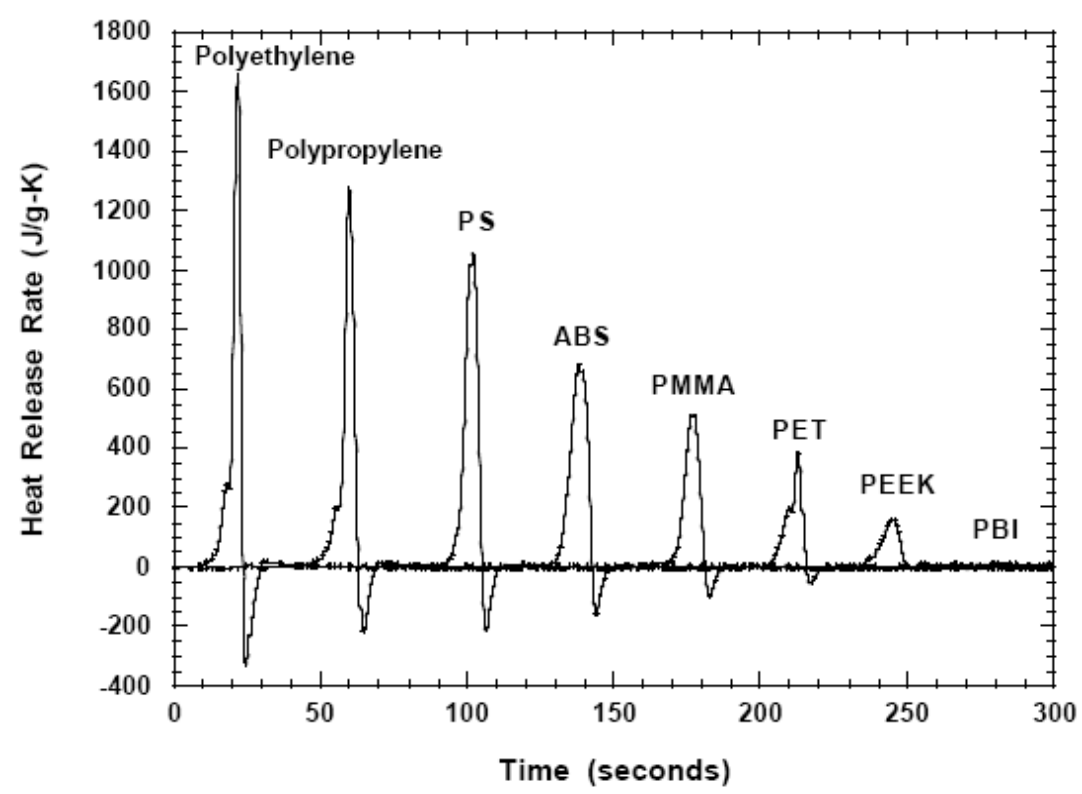

Figure 2. $\quad$ Specific Heat Release Rate for Several Polymers. ${ }^{16}$

\section{PEEK Decomposition and Flammability}

PEEK has superior thermal degradation resistance, with a continuous use temperature of $260^{\circ} \mathrm{C}$ and a melting point of $343^{\circ} \mathrm{C} .^{17}$ The onset of thermal degradation resulting in mass loss occurs between $575-580^{\circ} \mathrm{C} .{ }^{18}$ As shown in Table 1 , this number is quite noteworthy in comparison to the other polymers listed. 
Although the thermal decomposition of PEEK is different in both oxygen and nitrogen environments, both show two step decomposition processes. Figure 3 shows how the weight loss and thermal decomposition of PEEK and its composites proceeds in a nitrogen environment. In the first decomposition step, random chain scission of the ether and ketone bonds is believed to be the main mechanism. ${ }^{19}$ However, cleavage of the carbonyl bond will lead to radical intermediates that are more stable due to resonance effects and would be expected to predominate.

Table 1. Comparison Of Onset Of Decomposition Temperatures Of Various Polymers

\begin{tabular}{|l|c|}
\hline Polymer & $\begin{array}{r}\text { Decomposition Onset Temperature } \\
\left({ }^{\circ} \mathrm{C}\right)\end{array}$ \\
\hline Polyethylene (PE) & 335 \\
\hline Polypropylene (PP) & 328 \\
\hline Polyvinyl chloride (PVC) & 200 \\
\hline Polystyrene (PS) & 285 \\
\hline Polymethyl methacrylate (PMMA) & 170 \\
\hline Polyethylene terephthlate (PET) & 283 \\
\hline Polycarbonate (PC) & 420 \\
\hline Polytetrafluoroethylene (PTFE) & 508 \\
\hline Polyetheretherketone (PEEK) & 575 \\
\hline
\end{tabular}




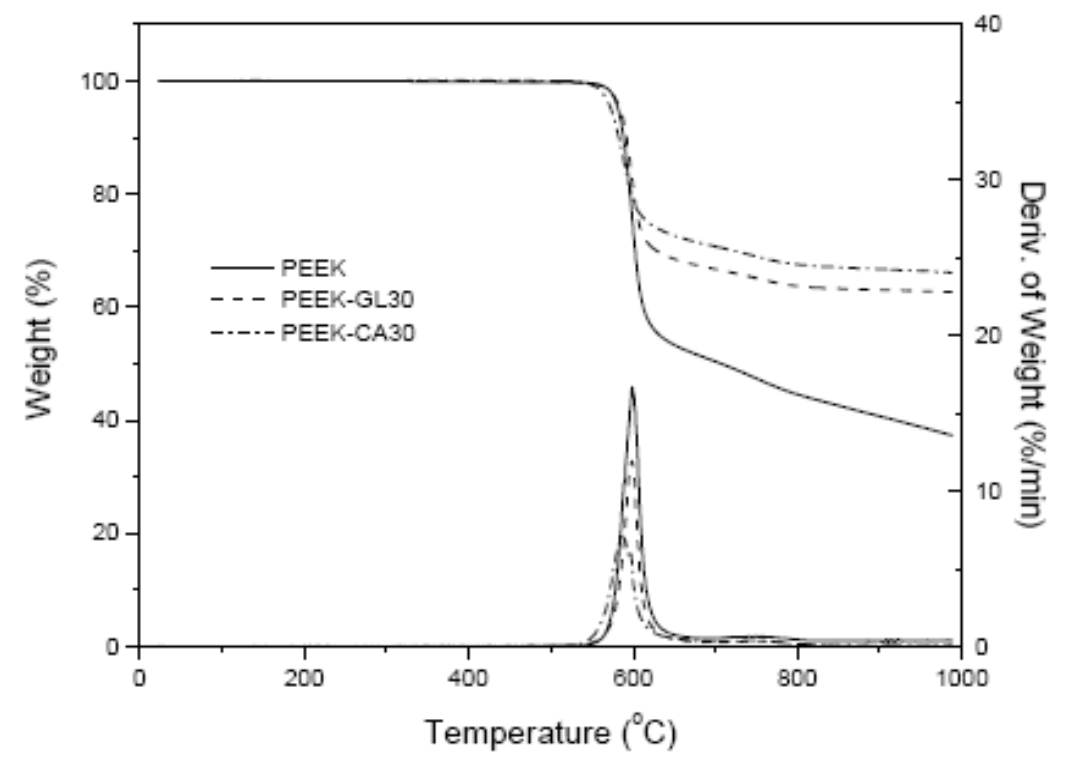

Figure 3. Thermal Decomposition of PEEK and its Glass (GL30) and Carbon (CA30) Fibre Composites Under Nitrogen. ${ }^{18}$

Rapid and significant mass loss occurs just below $600^{\circ} \mathrm{C}$ resulting in the volatilisation of around $45 \%$ of the polymer mass, the remaining polymer mass appears to be carbonaceous char. This has also been observed by other authors and has been attributed to the loss of, mainly, phenols as decomposition products, ${ }^{21}$ although carbon monoxide (CO) and carbon dioxide $\left(\mathrm{CO}_{2}\right)$ have also been identified as evolving rapidly over this temperature range, ${ }^{22}$ possibly as a by-product of the decomposition of PEEK to phenols. This is followed by a slower process of volatilisation of the residue, with over $35 \%$ still present even at $1000^{\circ} \mathrm{C}$. In the presence of $30 \%$ glass fibre (PEEK-GL30), rapid mass loss also occurs just below $600^{\circ} \mathrm{C}$ resulting in the volatilisation of only around $25 \%$ of the polymer mass when compared to the unmodified PEEK. This lower mass loss is even more pronounced in the presence of $30 \%$ carbon fibre (PEEK-CA30), where only $20 \%$ of the mass is lost at the same temperature. At elevated temperatures, the presence of glass and carbon fibres continue to inhibit the decomposition with yields of residues at $1000^{\circ} \mathrm{C}$ of $65 \%$ and $70 \%$, respectively.

Figure 4 shows the same materials and their decomposition processes in air. In this instance, the second decomposition step is attributed to the oxidation of the carbonaceous char formed as a result of the first decomposition step. ${ }^{18}$ This step takes place at a slightly lower temperature for PEEK-CA30 than for pure PEEK and PEEK-GL30 indicating, as might be expected, that PEEK-CA30 is more readily oxidised. Oxidation of pure PEEK and 
PEEK-GL30 occurs at around the same temperature, although the latter ceases losing weight at around $700^{\circ} \mathrm{C}$. In comparison to pure PEEK and PEEK-CA30, PEEK-GL30 retains around $30 \%$ of its mass at elevated temperatures indicating that, as expected, the $30 \%$ by weight of glass fibres are not oxidised.

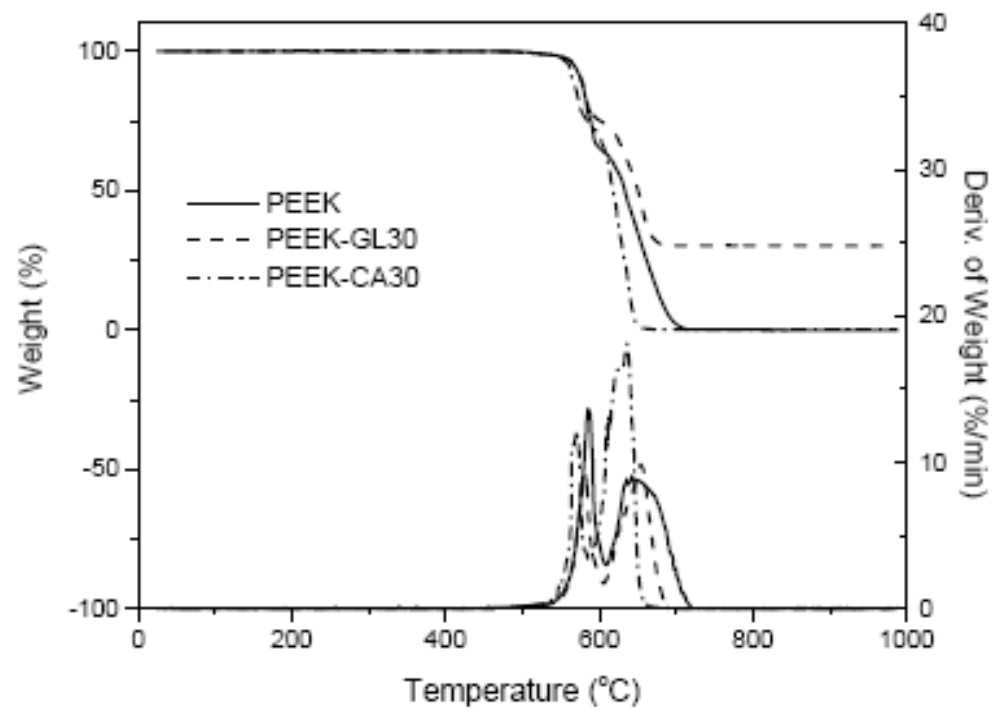

Figure 4. Thermal Decomposition of PEEK and its Glass (GL30) and Carbon (CA30) Fibre Composites in Air. ${ }^{18}$

The burning behaviour of PEEK and its composites differ in heat release rate (HRR) and total heat released (THR). This is depicted in Figure 5. These parameters are commonly determined using the Cone Calorimeter as described in ISO $5660^{23}$ where heat release rate is calculated based on the principle of oxygen consumption.

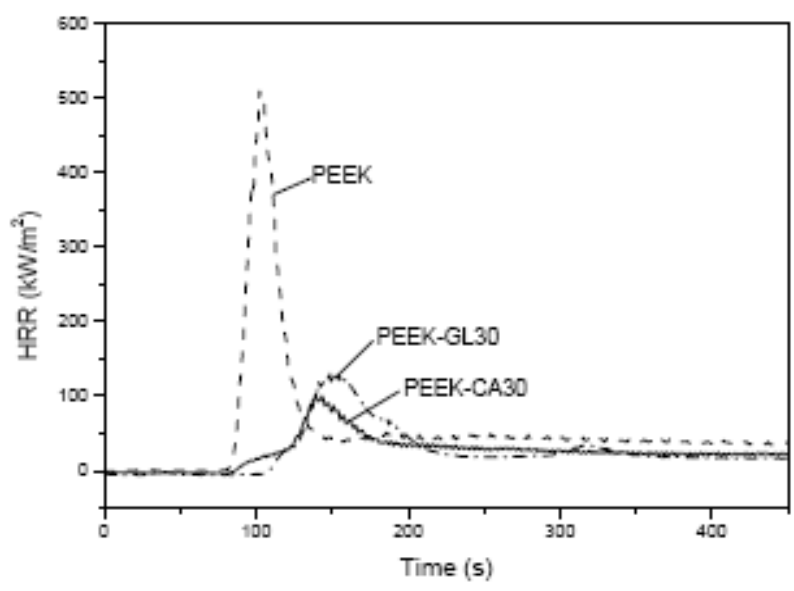

Figure 5. Cone Calorimeter Heat Release Curves of PEEK and its Composites. ${ }^{18}$ 
It can be seen that with $30 \%$ of the filler present, the heat release rate and total heat released is reduced by around $75 \%$ for the composites. There are several possible explanations for this. Under a flame, the oxygen concentration is close to zero ${ }^{24}$ and nitrogen-like decomposition would be observed, as the similarity between PEEK-CA30 and PEEK GL-30 in a nitrogen atmosphere and the cone calorimeter indicates. The lower heat release rate of modified PEEK is thought to be due to the mass-dilution effect, where the total amount of burning materials is reduced ${ }^{18}$ giving a greater char yield as shown in Table 2. It is also accepted that in charring systems, the presence of fillers increase melt viscosity and suppress heat radiation and physical modification of the char. ${ }^{18}$ As an example, the presence of glass fibre can reduce melt flow and dripping to prevent the spread of flames in a fire. ${ }^{18}$

Table 2. Char Yield (\%) for PEEK and its Composites under Nitrogen. ${ }^{18}$

\begin{tabular}{|l|c|}
\hline Polymer & Char \% (in $\mathbf{N}_{\mathbf{2}}$ ) \\
\hline PEEK & 41 \\
\hline PEEK-CA 30 & 67 \\
\hline PEEK-GL 30 & 63 \\
\hline
\end{tabular}

As seen in Figure 5, the time to ignition increases in the presence of glass fibre, but not carbon fibre. Conversely, in the presence of carbon fibre, the increase in heat release rate is more gradual.

\section{PEEK Decomposition - Products and Mechanisms}

The main products of PEEK decomposition have been identified as $\mathrm{CO}, \mathrm{CO}_{2}$, phenols and some aromatic ethers. ${ }^{18}$ It has been proposed that the decomposition of PEEK occurs through competing mechanisms. These are mainly chain scission, leading to volatile fuel formation, and cross-linking, leading to char formation. ${ }^{25}$ PEEK decomposition is initiated by random homolytic scission of either the ether or the carbonyl bonds in the polymer chain, ${ }^{26}$ although there is disagreement as to which of these bonds is more stable. It is 
believed that as most of the products of PEEK decomposition contain terminal hydroxyl groups and there are few with aldehyde units that the ether links are less thermally stable. ${ }^{21}$

Furthermore, work has been carried out on the initial decomposition of PEEK and its products using coupled techniques such as Thermogravimetry/Mass Spectometery (TG/MS) ${ }^{19}$ and Pyrolysis Gas Chromatography/Mass Spectrometry (pyGC/MS) ${ }^{22}$ as well as a combination of the two. ${ }^{27}$ Table 3 shows the volatile decomposition products of PEEK determined by stepwise pyGC/MS arranged by peak temperature of production.

Table 3. Decomposition Products of PEEK by Temperature - Flash pyGC/MS. ${ }^{22}$

\begin{tabular}{|l|l|}
\hline Temperature & Decomposition Product \\
\hline $450^{\circ} \mathrm{C}$ & 4 -Phenoxyphenol \\
\hline $650^{\circ} \mathrm{C}$ & $\mathrm{CO}+\mathrm{CO}_{2}$ \\
\hline & Diphenyl ether \\
\hline $750^{\circ} \mathrm{C}$ & Phenol \\
\hline & Benzene \\
\hline & Dibenzofuran \\
\hline & Hydroquinone \\
\hline & 4 -Dibenzofuranol \\
\hline & 4 -Hydroxybenzophenone \\
\hline & p-Benzoquinone \\
\hline & Benzophenone \\
\hline & Biphenyl \\
\hline & Naphthalene \\
\hline & Fluorene \\
\hline & $4-$ Hydroxybenzophenone \\
\hline & 4-Phenylphenol \\
\hline &
\end{tabular}


In the first stage of decomposition, pyGC/MS has identified 1,4-diphenoxybenzene and 4-phenoxyphenol as products at $450^{\circ} \mathrm{C},{ }^{22}$ indicating that the degradation of PEEK is initiated by cleavage at chain ends and branches.<smiles>c1ccc(Oc2ccc(Oc3ccccc3)cc2)cc1</smiles>

1,4 - Diphenoxybenzene<smiles>Oc1ccc(Oc2ccccc2)cc1</smiles>

4 - Phenoxyphenol

Figure 6. Major PEEK Degradation Products at $450^{\circ} \mathrm{C}$.

At higher temperatures, decomposition products contain lower molecular weight volatiles such diphenyl ether as well as benzene and methylbenzene. As the randomness of the main chain scission increases, other volatile products such as diphenyl ether and CO and $\mathrm{CO}_{2}$ are formed at $650^{\circ} \mathrm{C}$ and dibenzofuran, biphenyl and naphthalene at and above $750^{\circ} \mathrm{C} .^{22}$

At temperatures above $650^{\circ} \mathrm{C}$, chain cleavage at terminal carbonyls is believed to be the primary pyrolysis pathway. Phenol has been identified as a major decomposition product, its yield being greater than benzene at temperatures above $650^{\circ} \mathrm{C} .{ }^{27}$ In addition, dibenzofuran has also been identified as another major decomposition product; its structure (Figure 7) can be related to the ring closure between diradicals at the ether groups of the PEEK monomer unit.

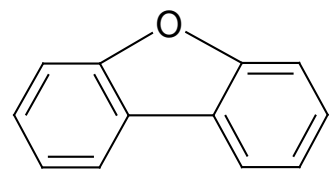

Dibenzofuran

\section{Figure 7. Dibenzofuran}

Dibenzofuran is produced at a peak pyrolysis temperature of $750^{\circ} \mathrm{C}$, a high temperature environment which is believed to favour the recombination of adjacent radicals to form dibenzofuran derivatives. The following mechanism has been proposed: ${ }^{22}$ 


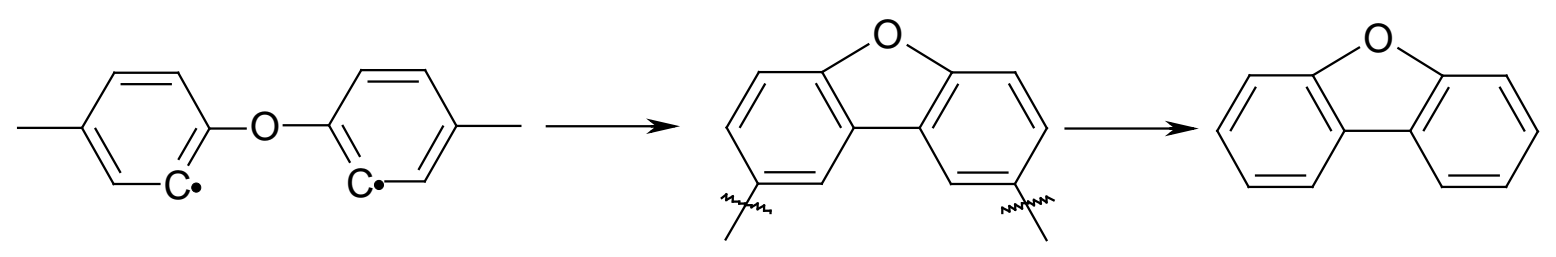

Figure 8. Recombination of Adjacent Radicals to form Dibenzofuran. ${ }^{22}$

Dibenzofuran has also been identified in the decomposition products of poly(1,4phenylene oxide) and is commonly observed as a dimer, ${ }^{21}$ but the corresponding carbonyl derivative was not observed indicating that the ether group is more stable than the ketone group. However, work completed by Tsai et al found benzophenone to be a minor product of PEEK decomposition at a peak pyrolysis temperature of $750^{\circ} \mathrm{C}$. Its structure (Figure 9) could be linked to a dibenzofuran carbonyl derivative that has also been found in Thermogravimetric - Mass Spectrometry (TG/MS) traces. ${ }^{19}$<smiles>O=C(OCCCCOc1ccccc1)c1ccccc1</smiles>

Figure 9. Benzophenone

The yield of phenol has been determined as being two to three times greater than that of benzene in samples which were subjected to $1500^{\circ} \mathrm{C}$ in a pyGC/MS . This is increased to a yield twenty times greater under dynamic $\left(10^{\circ} \mathrm{C} /\right.$ minute $)$ TGA heating rates in a nitrogen atmosphere. $^{27}$ It is proposed that breaking the ether linkage produces phenolic radical end groups which, after hydrogen abstraction, leave phenol as the major decomposition product. Ether linked molecules have been found to be present amongst the products of pyrolysis indicating that breakage of the carbonyl bond is also occurring. ${ }^{27}$ It is believed that cleavage of the ether group occurs at lower temperatures to yield phenol as a major product of decomposition. In contrast, decomposition of the carbonyl group, occurring at higher temperatures, yields $\mathrm{CO}_{2}$ as a major product of pyrolysis. ${ }^{27}$

Species containing two aryl groups, such as biphenyl, naphthalene and fluorene show similar patterns of formation. All have a peak pyrolysis temperature of $650^{\circ} \mathrm{C}$, reach 
maximum amounts at $750^{\circ} \mathrm{C}$ and decrease rapidly to trace amounts above $900^{\circ} \mathrm{C}^{22}$ This is similar to the pattern shown by dibenzofuran and so indicates that all are formed by the recombination of free radicals produced by ether or carbonyl scission of the main polymer chain. $^{22}$ This process produces biphenyl as shown (Figure 10):

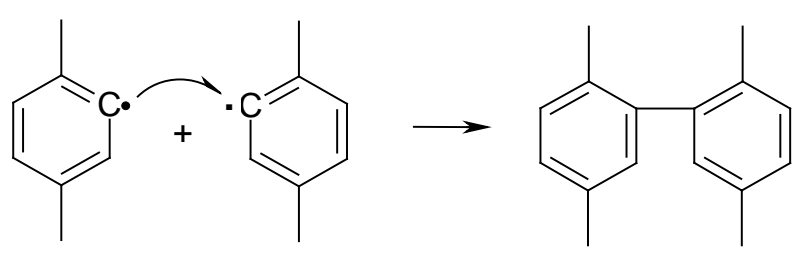

Figure 10. Recombination of Adjacent Radicals to form Biphenyls. ${ }^{22}$

Above $900^{\circ} \mathrm{C}$, significant amounts of phenyl phenol have been detected in the pyGCMS, possibly due to the continuing pyrolysis of ether-containing species in the incompletely carbonised solid residue. The mechanism for this is shown below (Figure 11):

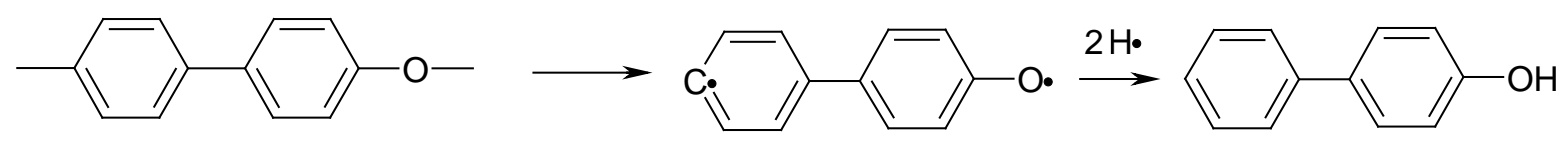

Figure 11. Pyrolysis of Solid Residues to Form Phenyl Phenol. ${ }^{22}$

A high char yield suggests that the random scission of the main chain is accompanied by carbonisation. pyGC/MS data indicates that carbonisation might be the dominant pyrolysis pathway at temperatures above $750^{\circ} \mathrm{C}^{22}$

Further analysis has been completed on PEEK that has been aged thermally to determine the early stages of the crosslinking mechanism, which results in a char-like residue. $^{28}$ It is believed that crosslinking occurs during the early stages of decomposition. ${ }^{21}$ PEEK samples aged thermally for 0.5 , 4 and 6 hours at $400^{\circ} \mathrm{C}$ in air, were analysed using ${ }^{13} \mathrm{C}$ Magic Angle Spinning Nuclear Magnetic Resonance spectroscopy (MASNMR). Differences in NMR spectra were found and as the thermal aging process was continued, there was a slight reduction in the ratio of the C-5 to C-6 and C-4 to C-7 resonances of the polymer, ${ }^{28}$ as indicated in Figure 12. 


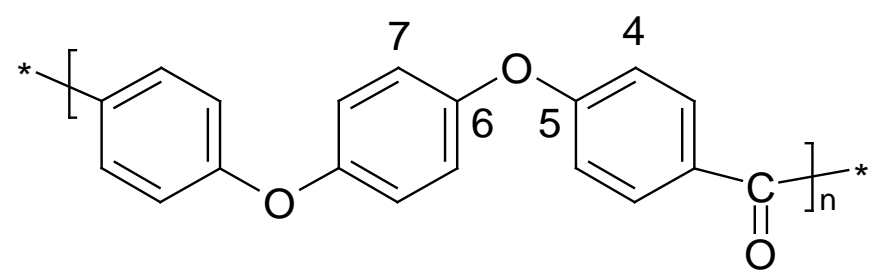

Figure 12. $\quad$ PEEK with Involved Carbons

These changes were found to be more significant for samples that were aged for longer periods of time, ${ }^{28}$ suggesting that the process may be kinetically unfavourable or that it involves a slow rearrangement process. Figure 13 shows a cross-linked product suggested by the changes in ratios of C-5 to C-6 and C-4 to C-7. The authors did not report either the alkyl $\mathrm{CH}_{2}$ signal (from C-4 at ca. $40 \mathrm{ppm}$ ) or the quaternary C-O (from C-5 at ca. $65 \mathrm{ppm}$ ), which the structure suggests should appear. However, this is not too surprising as the peaks could easily be obscured by spinning side bands or noise.

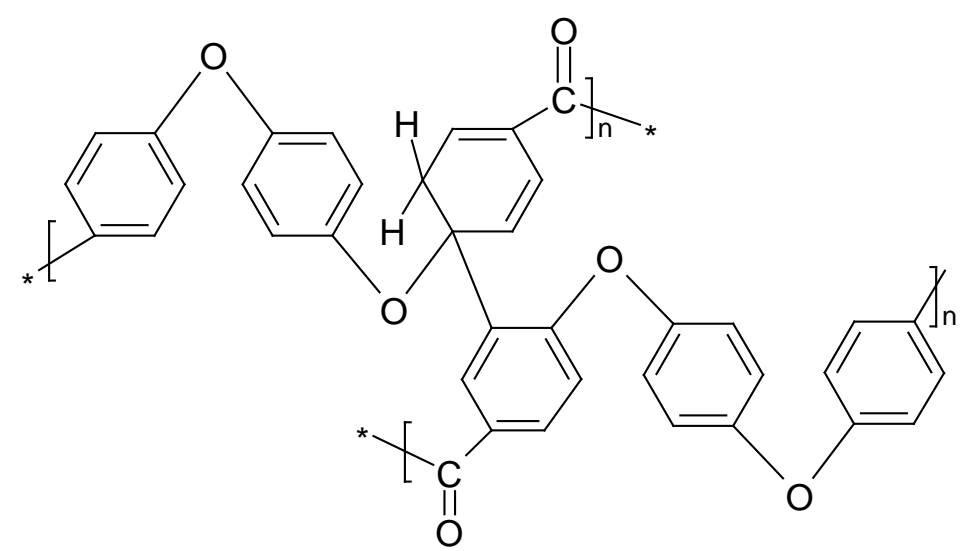

Figure 13. PEEK with Crosslinking between C-4 and C-5

\section{Discussion}

Suggested Mechanisms for the Formation of Major Products

Based on the identified volatile decomposition products, ${ }^{19,21,22.27,28}$ some mechanisms for their formation can be suggested. The following mechanistic schemes, arranged by peak temperature of appearance of the volatile product, are proposed. 
At $450^{\circ} \mathrm{C}$ 1,4-diphenoxybenzene and 4-phenoxyphenol are the main products. The easiest bond to break should be the carbonyl to aromatic ring bond as the two radicals from each scission are stabilised by resonance to phenoxy groups. The carbonyl radical produced could be oxidised in air to a carboxylic acid or converted to an aldehyde by hydrogen radical abstraction under anaerobic conditions. These products may contribute to foaming of the char and release of carbon dioxide and carbon monoxide, respectively, at $650^{\circ} \mathrm{C}$.

Scheme 1 - $450^{\circ} \mathrm{C}: 1,4-$ Diphenoxybenzene

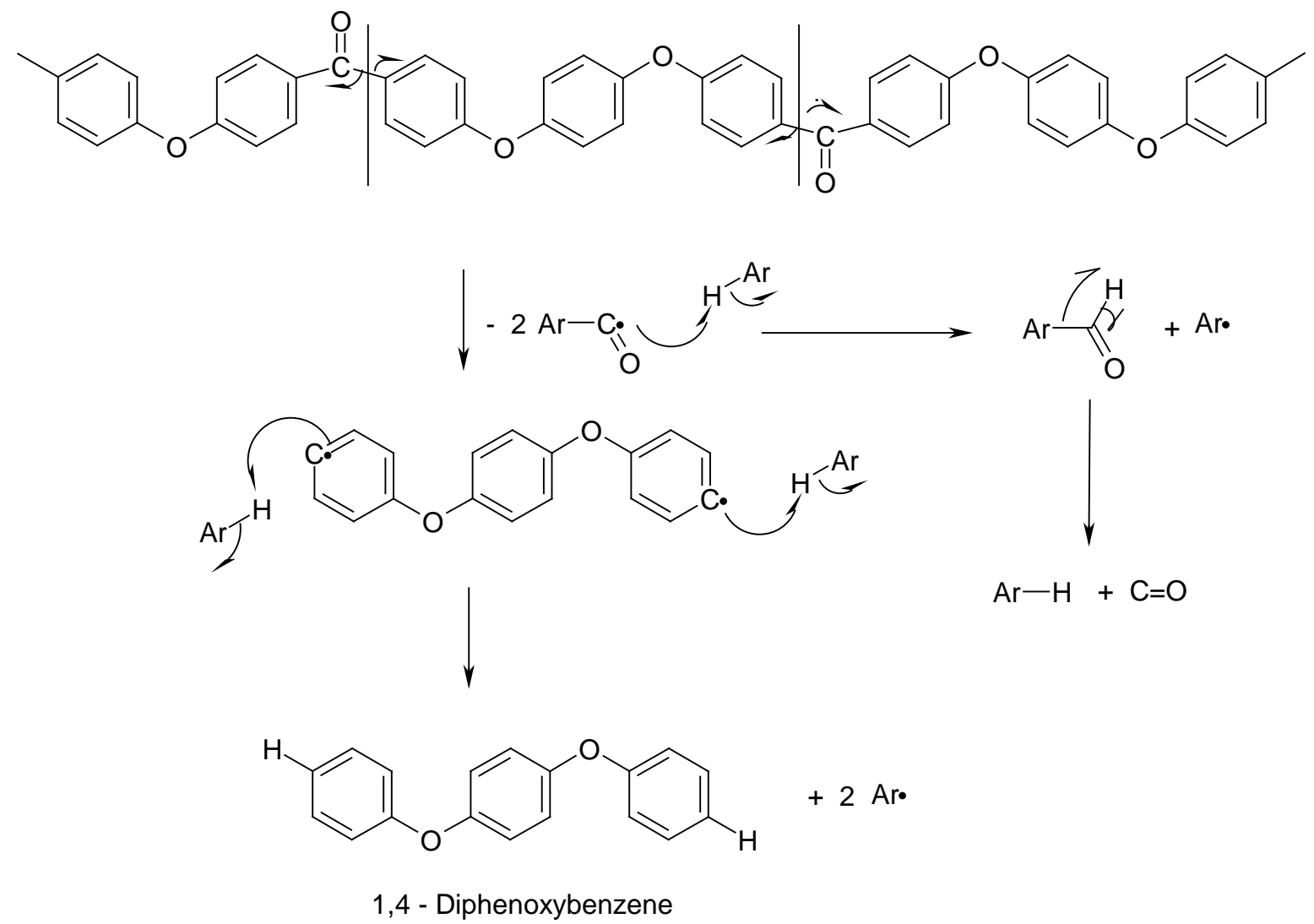

The next easiest bond to break is the ether oxygen to aromatic ring bond, as the phenoxy radical is stabilised by resonance to the aryl ketone ring. 
Scheme 2 - $450^{\circ} \mathrm{C}$ : 4-Phenoxyphenol

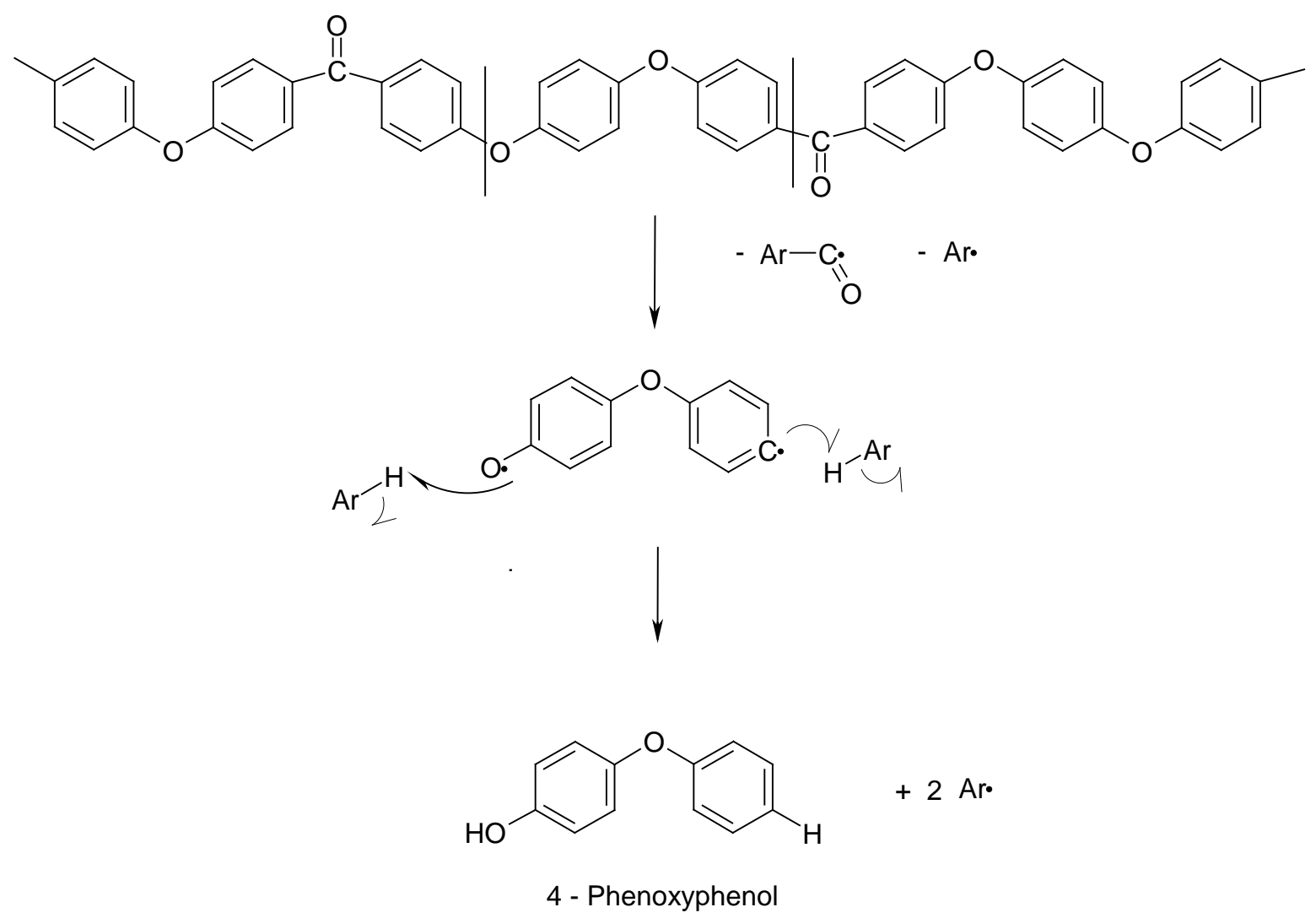

At $650^{\circ} \mathrm{C}$ diphenyl ether and phenol are formed. At this higher temperature, the bond breaking reactions require higher energy than needed for the formation of 4-phenoxyphenol at $450^{\circ} \mathrm{C}$ as the aryl and phenoxy radical intermediates do not have the extra resonance stabilisation of an aryl ketone or phenol ring. 
Scheme 3 - $650^{\circ} \mathrm{C}$ : Diphenyl ether and Phenol

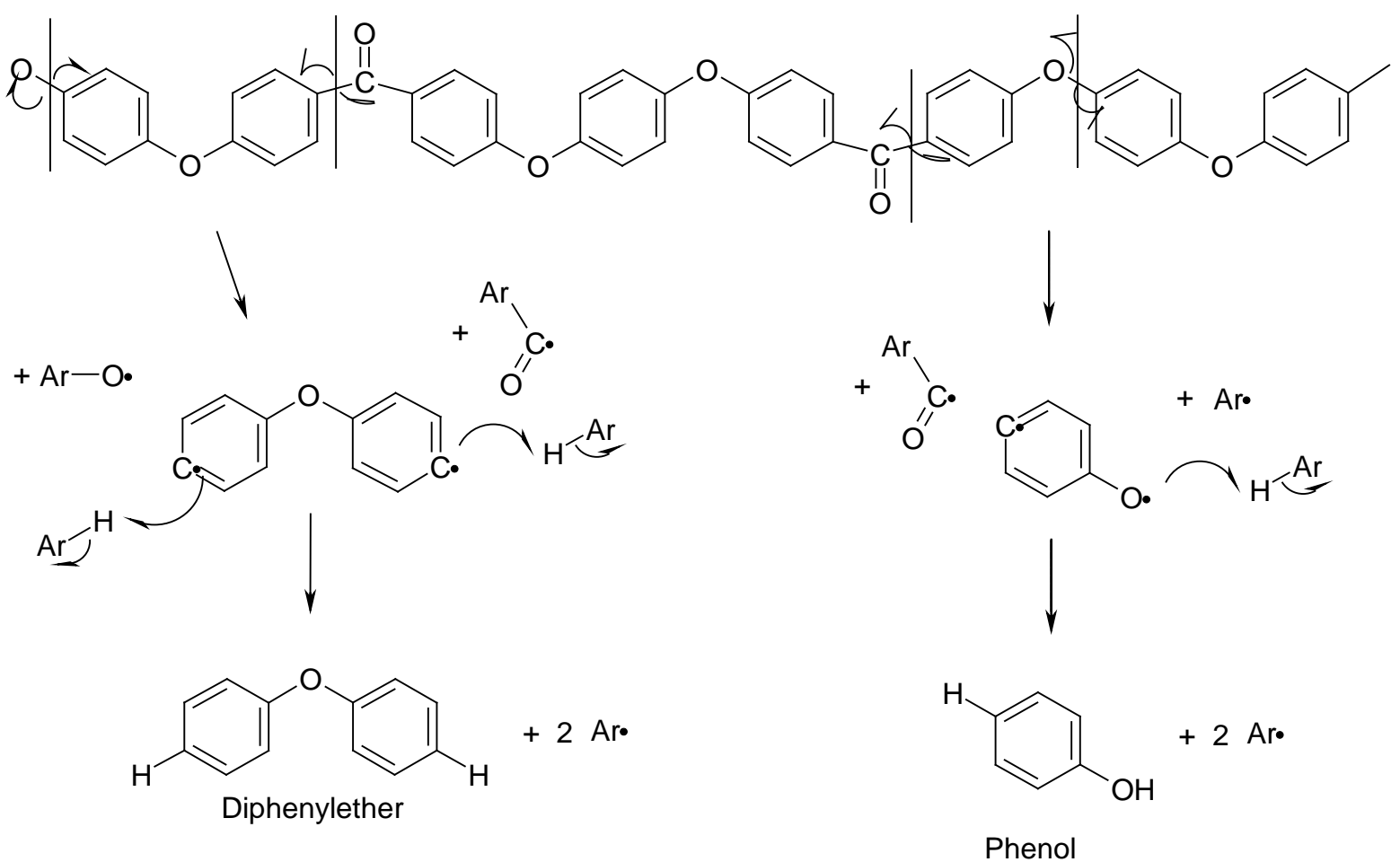

Also, at this temperature, pre-formed carboxylic acids can give carbon dioxide by decarboxylation and aldehydes can give carbon monoxide by decarbonylation.

At $750^{\circ} \mathrm{C}$ phenol formation continues and benzene formation begins. The diradicals shown below are almost certainly not formed, but for ease of representation, the diagram shows them present at the same time, however, in reality, this would be a stepwise process. 
Published in Polymer Degradation and Stability 95, 709-718, (2010)

doi:10.1016/j.polymdegradstab.2010.01.024

Scheme $4-750^{\circ} \mathrm{C}$ : Phenol and Benzene

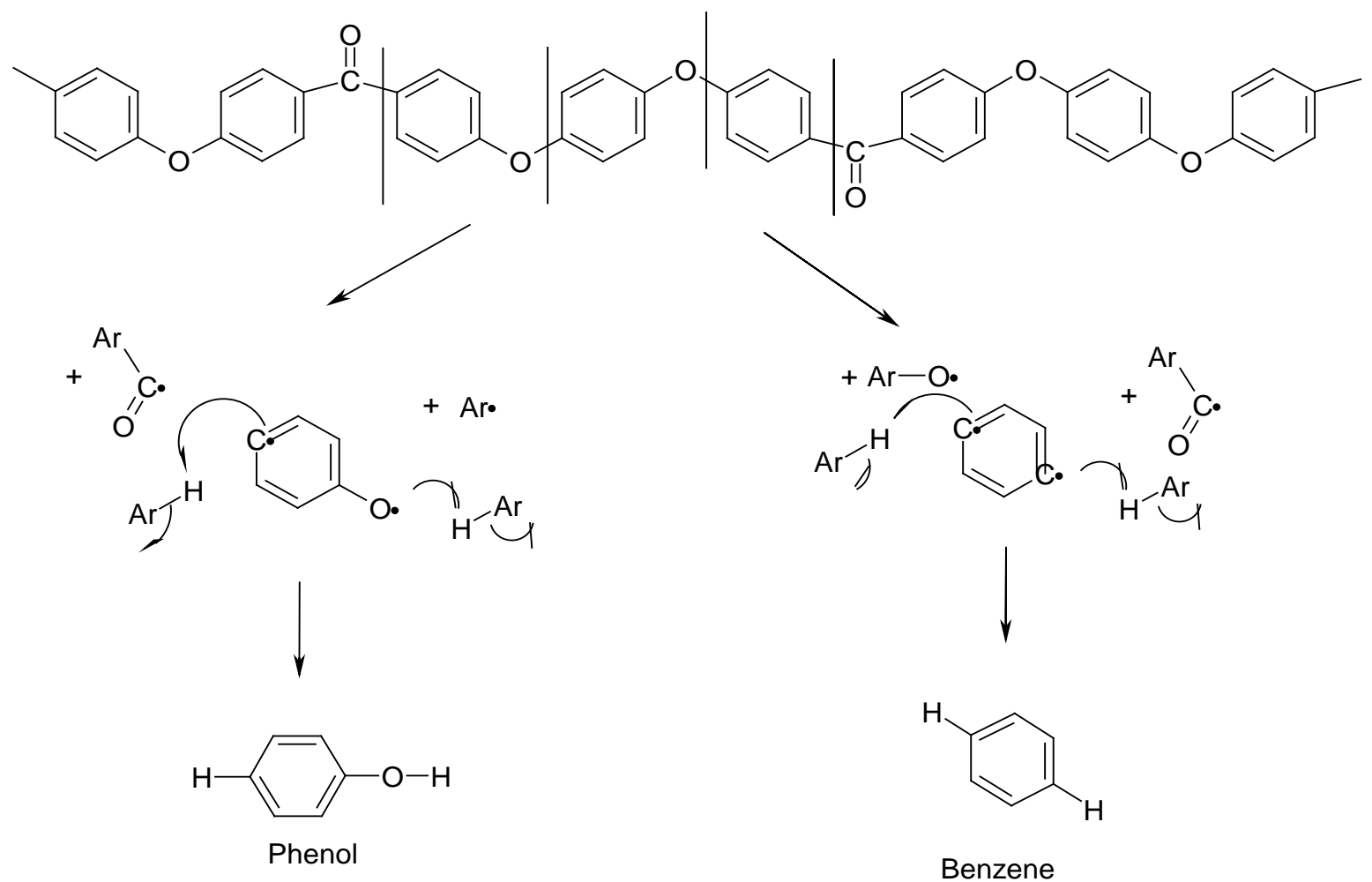

Hydroquinone and benzoquinone are also formed at $750^{\circ} \mathrm{C}$ and less stable radicals and diradicals can be formed at this temperature. A diradical pathway would probably lead to benzoquinone whilst a stepwise process would lead to hydroquinone.

Scheme 5 - $750^{\circ} \mathrm{C}$ : Hydroquinone and Benzoquinone

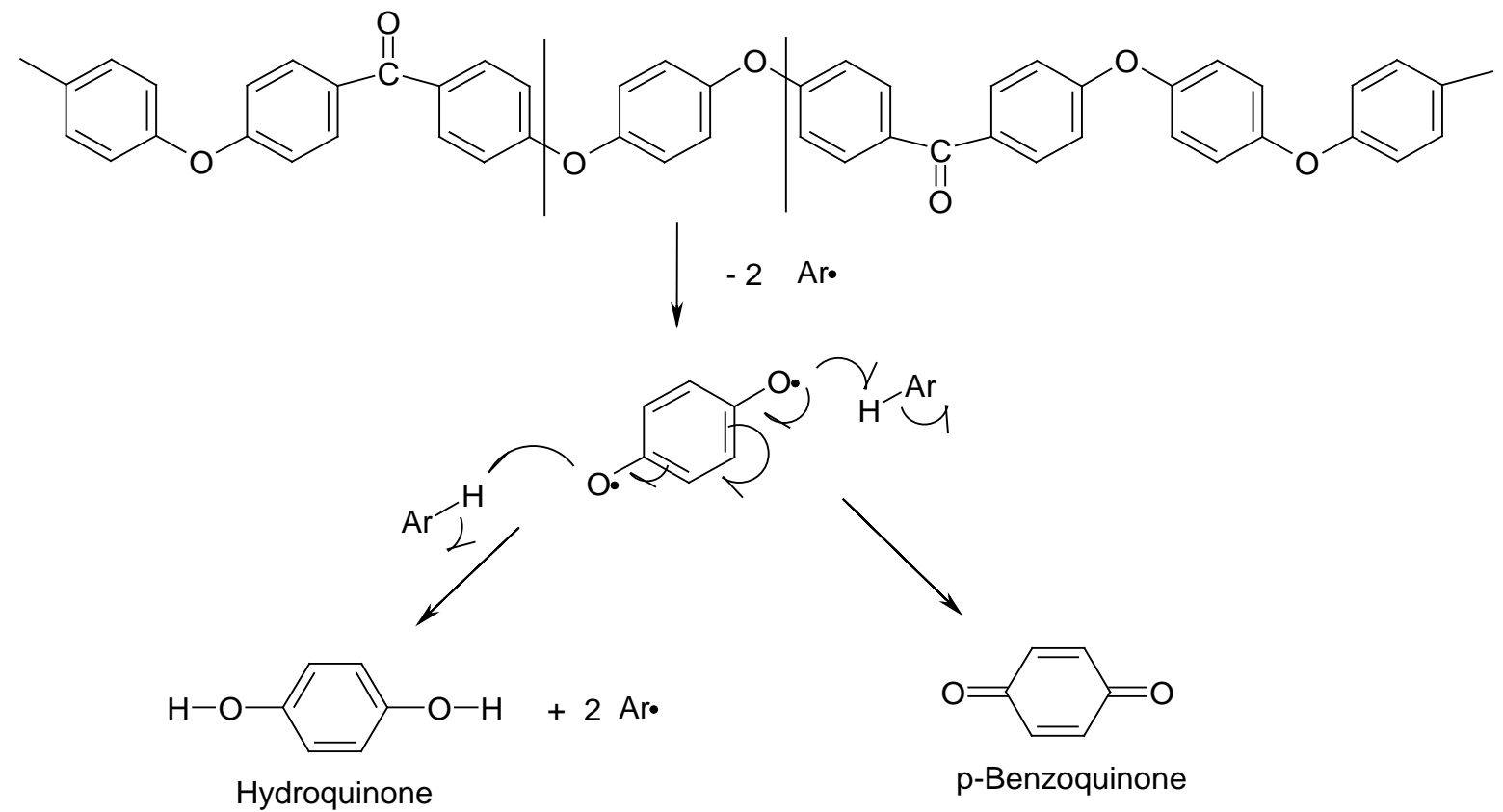


Published in Polymer Degradation and Stability 95, 709-718, (2010)

doi:10.1016/j.polymdegradstab.2010.01.024

The 2,2'-diradical shown below would be formed at lower temperatures and would ring close to form dibenzofuran rings in the polymer chain. Subsequent chain scissions at $750^{\circ} \mathrm{C}$ would lead to dibenzofuran and dibenzofuranol release.

Scheme 6 - $750^{\circ} \mathrm{C}$ : Dibenzofuran and Dibenzofuranol

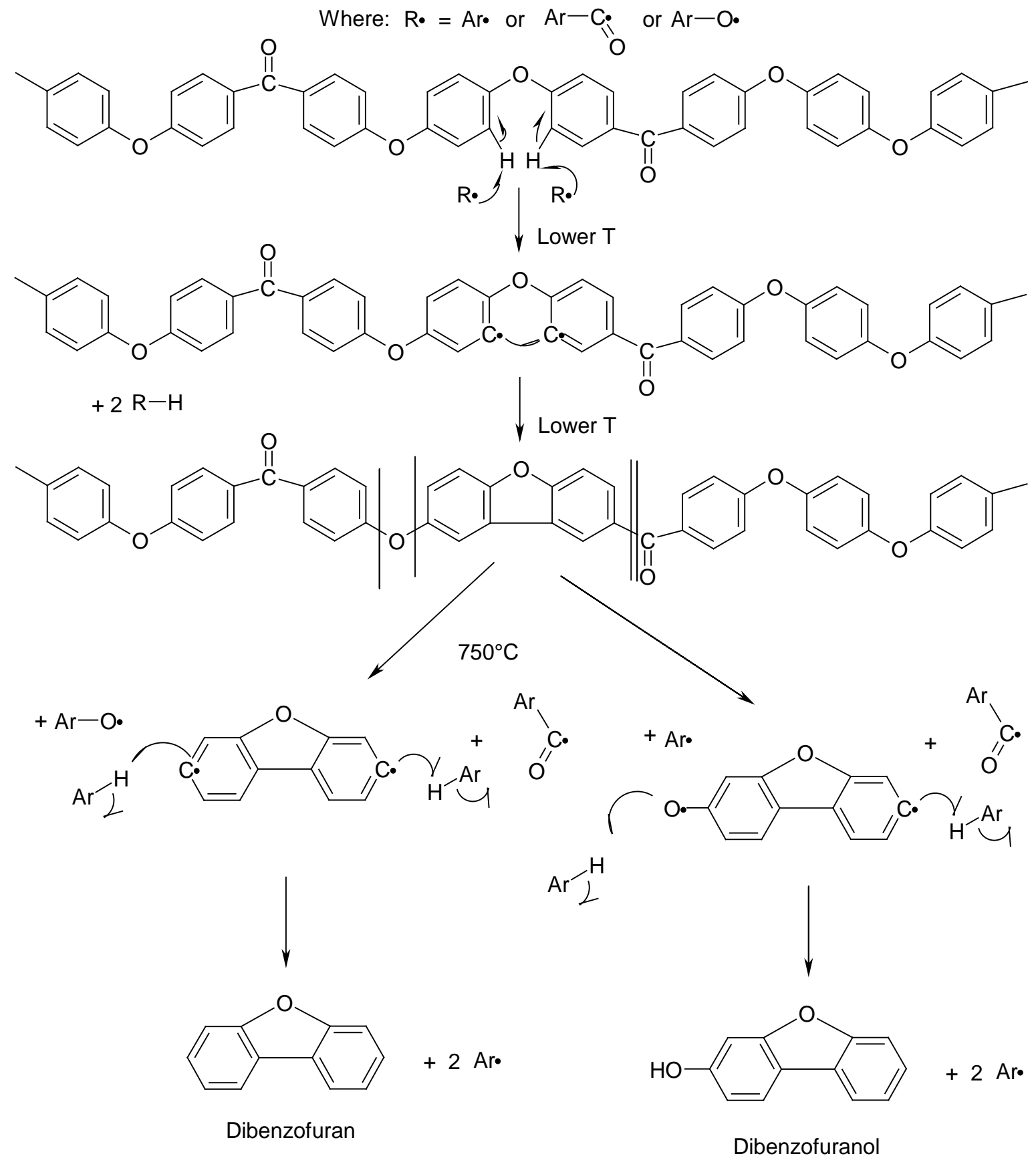


Published in Polymer Degradation and Stability 95, 709-718, (2010)

doi:10.1016/j.polymdegradstab.2010.01.024

Benzophenone diradicals will be of high energy due to the inductive electron withdrawing effect of the carbonyl, and so can only be formed at high temperatures by a stepwise process. These diradicals can abstract hydrogen atoms from nearby aromatic rings and form benzophenone.

Scheme $7-750^{\circ} \mathrm{C}$ : Benzophenone<smiles>CCOc1ccc(C(=O)c2ccc(Oc3ccc(C(=O)c4ccc(Oc5ccc(Oc6ccc(C)cc6)cc5)cc4)cc3)cc2)cc1</smiles>

Finally, biphenyl can be formed by two aromatic radicals bonding together to give a biphenyl group and further bond scissions will release the biphenyl molecule. 
Scheme $8-750^{\circ} \mathrm{C}$ : Biphenyl

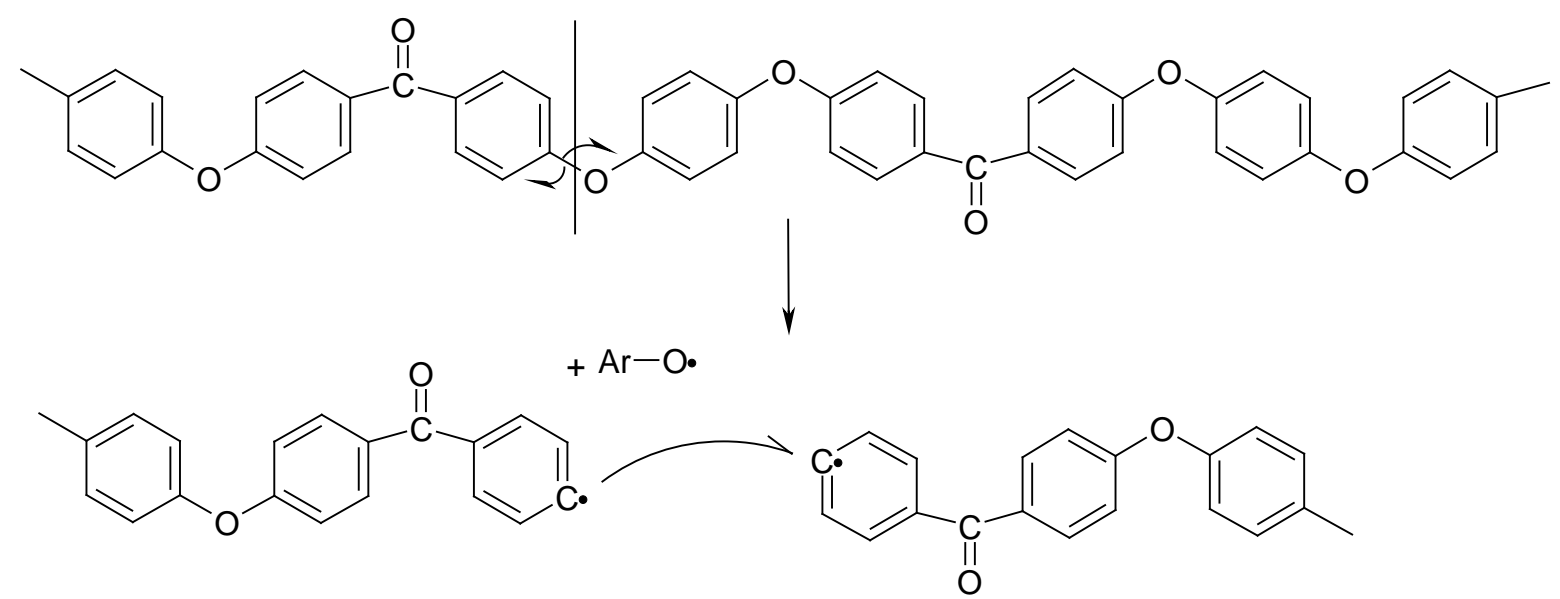

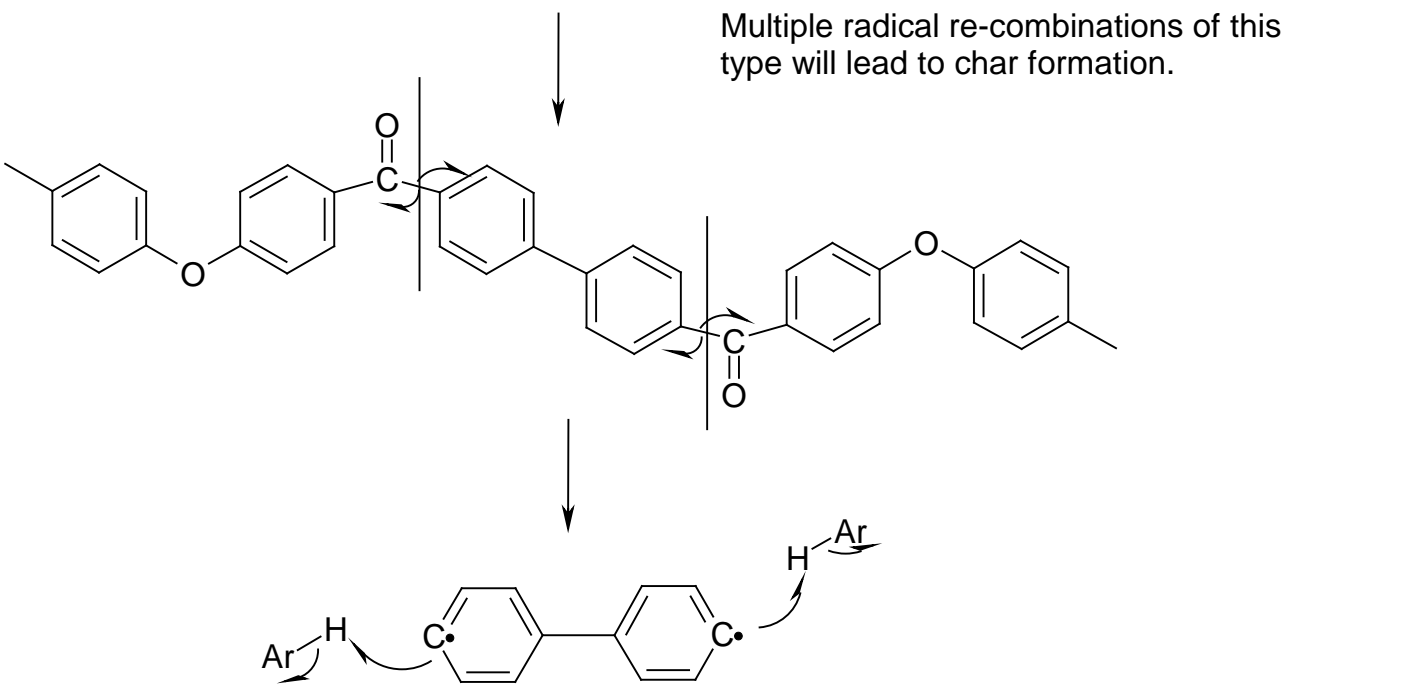<smiles>Ic1ccc(-c2ccccc2)cc1</smiles>

Biphenyl

Char formation (graphitisation) begins at around $650^{\circ} \mathrm{C}$ and continues to over $1000^{\circ} \mathrm{C}$. One possible mechanism to explain this involves the formation of radical sites on adjacent benzene rings attached to a carbonyl to give a 9H-fluoren-9-one, which can eliminate carbon monoxide to produce a diradical. The diradical can cyclise with another aromatic radical nearby and then re-aromatise to begin formation of an extended aromatic array, graphite. Whilst fluorenones are not found in the gaseous phase, they have been 
Published in Polymer Degradation and Stability 95, 709-718, (2010)

doi:10.1016/j.polymdegradstab.2010.01.024

detected in the solid phase at between $400-500^{\circ} \mathrm{C}$ using FTIR spectroscopy on PEEK films. ${ }^{11}$ The ease of formation of graphite from the fluorenone structure probably explains the absence of such molecules from the gaseous products.

Scheme 9 - $650^{\circ}-1100^{\circ} \mathrm{C}$ : Graphitisation

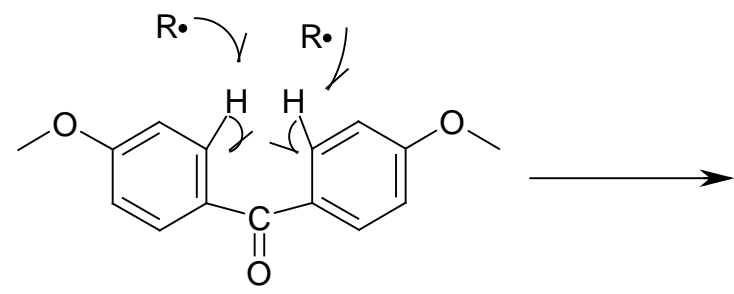<smiles>COc1ccc(C(=O)c2ccc(OC)cc2C)c(C)c1</smiles><smiles>COc1ccc2c(c1)-c1cc(OC)ccc1C2=O</smiles><smiles>COc1cccc(CCc2ccc(OC)cc2-c2ccc(OC)cc2-c2cccc(OC)c2)c1</smiles><smiles>COC1=CC2(C)c3ccc(OC)cc3-c3cc(OC)ccc3C2C(c2cccc(OC)c2)=C1</smiles><smiles>[R]CCCCCCCCC[R]</smiles>

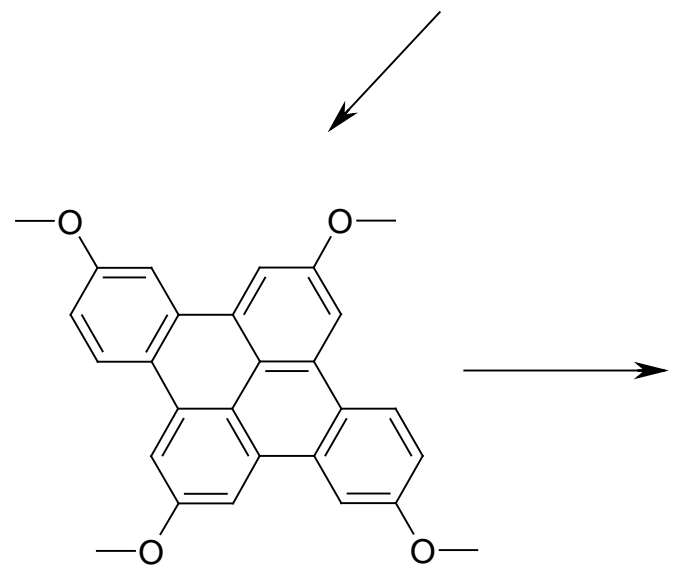

etc. to graphitisation 


\section{Conclusions}

Whilst much can be inferred about the mechanism of thermal decomposition of PEEK from the volatile organic products formed at various temperatures; the reactions in the melt also need to be elucidated to provide a more concise understanding of the actual mechanisms occurring. This will lead to better control of the thermal decomposition properties and help explain the role of fillers in altering the onset of mass loss and promotion of char formation. However, little work has been done to confirm the presence of the inferred products and intermediates in the solid/melt phase, thus suggesting that in future it would be fruitful to concentrate on the reactions occurring in the melt.

\section{References}

\footnotetext{
${ }^{1}$ Murari, A. and Barzon, A., (2003), "Comparison of new PEEK Seals with Traditional Helicoflex for Ultra High Vacuum Applications”, Vacuum, 72(3), 327-334.

${ }^{2}$ Yao, F., Zheng, J., Qi, M., Wang, W. and Qi, Z., (1991), “The Thermal Decomposition Kinetics of Poly(Ether-Ether-Ketone) (PEEK) and its Carbon Fibre Composite”, Thermochimica Acta, 183, 91-97.
}

${ }^{3}$ Nandan, B., Kandpal, L., and Mathur, G. N., (2002), "Poly(Ether Ether Ketone)/Poly(Aryl Ether Sulphone) Blends: Thermal Degradation Behaviour”, European Polymer Journal, 39(1), 193-198.

${ }^{4}$ Narrakh, M., Ellis, G., Gomez, M., and Marco, C., (1999), "Thermal Decomposition Of Technological Polymer Blends. 1. Poly(Aryl Ether Ether Ketone) With A Thermotropic Liquid Crystalline Polymer”, Polymer Degradation And Stability, 66(3), 405-413.

${ }^{5}$ Nam, J. D., and Seferis, J. C., (1992), “Generalised Composite Degradation Kinetics For Polymeric Systems Under Isothermal And Nonisothermal Conditions”, Journal Of Polymer Science, 30(5), 455-463.

${ }^{6}$ Huo, R., Luo, Y., Liang, L., Jin, X., and Karasz, F. E., (1990), “Kinetic Studies On Thermal Degradation Of Poly(Aryl Ether Ether Ketone) And Sulphonated Poly(Aryl Ether Ether Ketone) By Thermogravimetry”, Journal Of Functional Polymers, 4, 426-433

${ }^{7}$ Day, M., Cooney, J. D., and Wiles, D. M., (1989), “The Kinetics Of The Oxidative Degradation Of Poly(Aryl-Ether-Ether-Ketone) (PEEK)”, Thermochimica Acta, 147(1), 189197. 
${ }^{8}$ Day, M., Cooney, J. D., and Wiles D. M., (1989), “The Thermal Stability Of Poly(Aryl Ather Ether Ketone) As Assessed By Thermogravimetry”, Journal Of Applied Polymer Science, 38(2), 323-337.

${ }^{9}$ He, J., Duan, X., ans Wang, Z.-X., (1997), “Study On The Kinetics And Mechanism Of Thermal Degradation Of PEEK By Temperature Programmed Decomposition”, Acta Chimica Sinica, 55(12), 1152-1157.

${ }^{10}$ Cole, K. C., and Casella, I. G., (1993), "Fourier Transform Infrared Spectroscopic Study Of Thermal Degradation In Poly(Ether Ether Ketone) - Carbon Composites”, Polymer, 34(4), 740-745.

${ }^{11}$ Cole, K. C., and Casella, I. G., (1992), "Fourier Transform Infrared Spectroscopic Study Of Thermal Degradation In Films Of Poly(Ether Ether Ketone)”, Thermochimica Acta, 211, 209-228.

${ }^{12}$ Yesodha, S. K., Pillai, C. K. S. and Tsutsuni, N., (2004), "Stable Polymeric Materials for Non-Linear Optics: A Review Based on Azobenzene Systems”, Progress in Polymer Science, 29(1), 45-74.

${ }^{13}$ Stevens, M. P., (1999), Polymer Chemistry: An Introduction. Third Edition. Oxford University Press, New York, USA.

${ }^{14}$ Kashiwagi, T., (1994), "Polymer Combustion and Flammability - Role of the Condensed Phase”, Twenty-Fifth Symposium (International) on Combustion /The Combustion Institute, 1423-1437.

${ }^{15}$ Walters, R. N., (2002), “Molar Group Contributions To The Heat Of Combustion”. Fire And Materials, 26, 131-145.

${ }^{16}$ Walters, R. and Lyon, R. E., (2001), “Calculating Polymer Flammability from Molar Group Calculations”. US Department Of Transport, Report Number: DOT/FAA/AR-01/31.

${ }^{17}$ Kuo, M. C., Tsai, C. M., Huang, J. C. and Chen, M., (2005), "PEEK Composites Reinforced by Nano-Sized $\mathrm{SiO}_{2}$ and $\mathrm{Al}_{2} \mathrm{O}_{3}$ Particulates", Materials Chemistry and Physics, 90, 185-195.

${ }^{18}$ Zhang, H., (2004), Fire-Safe Polymers and Polymer Composites, US Department Of Transport, Report Number: DOT/FAA/AR-04/11.

${ }^{19}$ Perng, L. H., Tsai, C. J. and Ling, Y. C., (1999), "Mechanism and Kinetic Modelling of PEEK Pyrolysis by TG/MS”, Polymer, 40, 7321-7329.

${ }^{20}$ Hilado, C., J., (1998), Flammability Handbook For Plastics. Fifth Edition. Chapter 2. Technomic Publishing Company Inc, Pennsylvania, USA.

${ }^{21}$ Hay, J. N. and Kemmish, D. J., (1987), “Thermal Decomposition of Poly(Aryl Ether Ketones)”, Polymer, 28, 2047-2051. 
${ }^{22}$ Tsai, C. J., Perng, L. H. and Ling, Y. C., (1997), “A Study of Thermal Degradation of Poly(Aryl-Ether-Ether-Ketone) using Stepwise Pyrolysis/Gas Chromatography/Mass Spectrometry”, Rapid Communications in Mass Spectrometry, 11, 1987-1995.

${ }^{23}$ ISO 5660-1: 1993. Fire Tests on Building Materials and Structures. Part 15-Method for Measuring the Rate of Heat Release of Products.

${ }^{24}$ Schartel, B., and Hull, T. R., (2007), “Application of Cone Calorimetry to the Development Of Materials With Improved Fire Performance”. Fire and Materials, 31, 327-354.

${ }^{25}$ Galloway, J., Hoffamn, R. and Bhatt, S., (2007), "Effect of Multiple Shear Histories on Rheological Behaviour And Devolatilisation of Poly (Ether Ether Ketone)”, ANTEC 3077.

${ }^{26}$ Nandan, B., Kandpal, L. D. and Mathur, G. N., (2003), "Poly(Ether Ether Ketone)/Poly(Aryl Ether Sulphone) Blends: Thermal Degradation Behaviour”, European Polymer Journal, 39, 193-198.

${ }^{27}$ Day, M., Cooney, J. D. and Wiles D. M., (1990), “The Thermal Degradation of Poly(Aryl Ether Ether Ketone) (PEEK) as Monitored by Pyrolysis-GC/MS and TG/MS”, Journal of Analytical and Applied Pyrolysis, 18, 163-173.

${ }^{28}$ Day, M., Sally, D. and Wiles, D. M., (1990), “Thermal Degradation of Poly(Aryl-EtherEther-Ketone): Experimental Evaluation of Crosslinking Reactions”, Journal of Applied Polymer Science, 40, 1615-1620. 